\title{
Singapore pulls plug on US collaboration
}

The Singaporean government is known for its generosity in pumping money into international research projects. But it can apparently be ruthless if these projects do not please it. The city-state is shutting down a medical research arm of Johns Hopkins University in Singapore, claiming it has not delivered as planned.

The decision has sent shock waves through other universities and research institutes, some of which are in the initial stages of collaborating with Singapore.

On 20 June, the 60 faculty members and staff of the Division of Biomedical Sciences, Johns Hopkins Medicine in Singapore, were given official notice that as of 1 June 2006, the facility was being wound down. The process will take 12 months, with researchers and staff receiving salaries until the facility closes on 31 May 2007.

"We thought it unwise to continue putting money into something that is not working," says Andre Wan, director of the Biomedical Research Council at the Agency for Science, Technology and Research (A`STAR). He claims that Johns Hopkins failed to meet key requirements in its contract.

The split is the first major failure of Singapore's recent push into biomedical research, which includes building the ambitious Biopolis research centre.

Singapore and Johns Hopkins Medicine first got together in 1998, to set up Johns Hopkins Singapore as the university's base for medical research, education and clinical studies in southeast Asia. In 2003, the two parties restructured the organization, making it the first full division of Johns Hopkins Medicine outside its US home in Baltimore, Maryland.

Under the five-year contract begun in February 2004, A*STAR agreed to provide $\$ \$ 75$ million (US\$47.5 million) to cover salaries, facilities

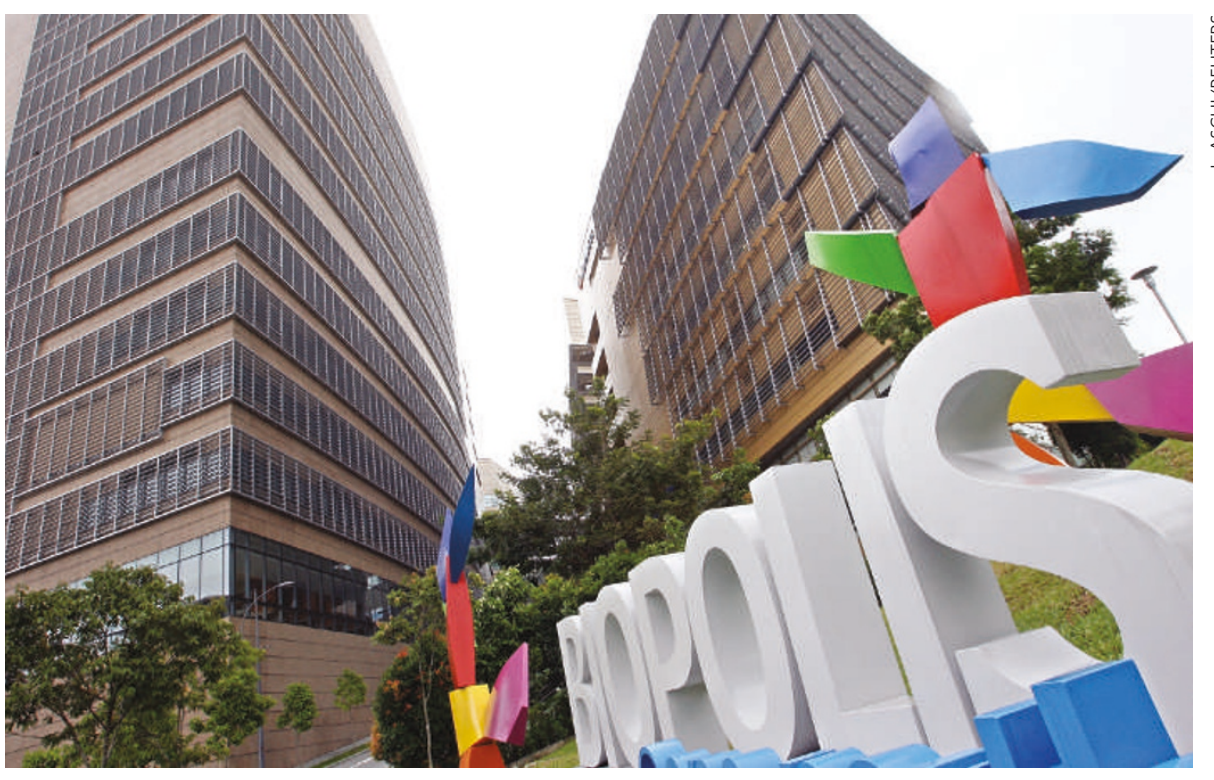

Singapore has the funds for grand research ventures such as Biopolis, but it demands results.

and research equipment. For its part, according to $A^{\star}$ STAR, Johns Hopkins aimed to build a centre of immunology, experimental therapeutics and cancer research, to establish a $\mathrm{PhD}$ programme and to bring senior researchers with international reputations to Singapore.

Wan alleges that Johns Hopkins has failed to meet 8 out of 13 key performance indicators in the past two years. For example, it agreed to hire at least 12 full-time senior researchers with residence in Singapore by the end of the second year. So far, Wan says it has hired seven, only one of whom fulfils all the requirements.

Gary Stephenson, a spokesman for Johns Hopkins Medicine, declined to comment, saying the university plans to issue a joint statement with $A^{\star}$ STAR soon. But on 22 July, a
Singaporean newspaper reported a Johns Hopkins official as alleging that Singapore failed to meet its financial and educational obligations under the agreement; $A^{\star}$ STAR denies those claims.

The break-up has reminded other universities not to take their collaborative projects with Singapore for granted. For instance, in 2005 Duke University School of Medicine in Durham, North Carolina, established a graduate medical school with the National University of Singapore, as part of a seven-year contract. "The major lesson I'm taking from this is to seek great clarity of how performance in our exciting new venture will be defined," says Sanders Williams, founding dean of the new school.

Ichiko Fuyuno the University of California, Irvine. "There was quite a bit - a lot - of scepticism in the community."

The sceptics included Scott Rychnovsky, also of Irvine. La Clair claimed that the structure of his compound matched a prediction made in 2002. But Rychnovsky worked out that hexacyclinol should resemble another mushroom compound, panepophenanthrin.

Rychnovsky teamed up with John Porco of Boston University, who came up with a new synthesis (J. A. Porco Jr et al. Angew. Chem. Int. Ed. doi:10.1002/anie.200602854; 2006).

The nuclear magnetic resonance (NMR) spectrum for the product matched the 2002 data, suggesting the team had made hexacyclinol. And the crystal structure confirmed their new prediction about its structure.

Which leaves chemists wondering how La Clair got results confirming the original - apparently wrong structure. And how such a controversial synthesis made it into a peer-reviewed journal. "I can't see any legitimate explanation for the original work," says Rychnovsky.

La Clair now says that he and Porco may have made two different molecules that happen to have very similar NMR spectra. He has no plans to retract his paper, but has offered to change the name of the compound he says he synthesized.

Because La Clair is unaffiliated with an institution other than the privately funded Xenobe, there is no obvious body to investigate what happened.

Peter Gölitz, editor of Angewandte Chemie, says La Clair's paper was recommended by three well-qualified reviewers. He declined to comment on whether the paper will be retracted. But he says he invited Rychnovsky to publish "so that the discussion and clarification can be done at the place where the original paper was published".

Emma Marris 